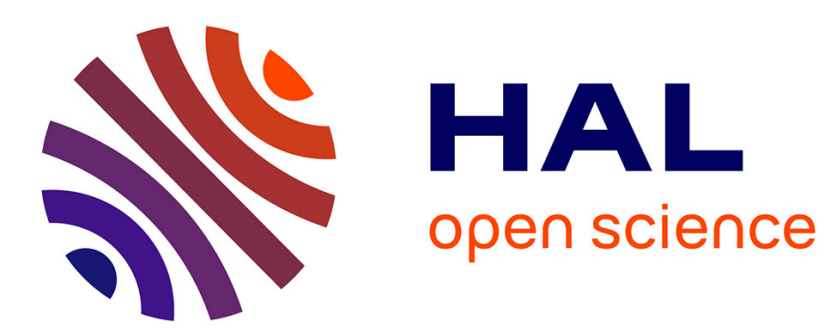

\title{
Non linear effects in monomode ytterbium doped silica fibers : cooperative luminescence
}

Y. Ouerdane, Sylvain Magne, M. Druetta, A. Boukenter, J. Goure, B. Jacquier

\section{To cite this version:}

Y. Ouerdane, Sylvain Magne, M. Druetta, A. Boukenter, J. Goure, et al.. Non linear effects in monomode ytterbium doped silica fibers : cooperative luminescence. Journal de Physique IV Proceedings, 1994, 04 (C4), pp.C4-545-C4-548. 10.1051/jp4:19944131 . jpa-00252583

\section{HAL Id: jpa-00252583 https://hal.science/jpa-00252583}

Submitted on 1 Jan 1994

HAL is a multi-disciplinary open access archive for the deposit and dissemination of scientific research documents, whether they are published or not. The documents may come from teaching and research institutions in France or abroad, or from public or private research centers.
L'archive ouverte pluridisciplinaire HAL, est destinée au dépôt et à la diffusion de documents scientifiques de niveau recherche, publiés ou non, émanant des établissements d'enseignement et de recherche français ou étrangers, des laboratoires publics ou privés. 


\title{
Non linear effects in monomode ytterbium doped silica fibers: cooperative luminescence
}

\author{
Y. OUERDANE, S. MAGNE*, M. DRUETTA, A. BOUKENTER, J.P. GOURE and \\ B. JACQUIER**
}

Laboratoire de Traitement du Signal et Instrumentation, URA 842 du CNRS, Université Jean Monnet, 23 nue Dr Paul Michelon, 42023 Saint Etienne, France

${ }^{*}$ Laboratoire de Mesures Optiques, CEA, LETI-DEIN-SPE, CEN Saclay, 91191 Gif-sur-Yvette cedex, France

** Laboratoire de Physico-Chimie des Matériaux Luminescents, URA 442 du CNRS, Université Claude Bernard, 69622 Villeurbanne, France

\begin{abstract}
The visible cooperative luminescence in Ytterbium-doped optical fibres was observed using a Titanium-Sapphire infrared laser excitation $(\cong 900 \mathrm{~nm})$. The evolution of this luminescence as a function of absorbed power is discussed. The optical confinement therefore enables us to observe new saturation effects which are studied for two different Ytterbium fibres.
\end{abstract}

We studied the visible fluorescence of two $\mathrm{Yb}^{3+}$-doped fibres pumped by a $\mathrm{CW}$ titanium-sapphire laser in the infrared range (from $840 \mathrm{~nm}$ to $975 \mathrm{~nm}$ ).

The fibre \# 1 (codoped with alumina) has a core of $2.1 \mu \mathrm{m}$ diameter and is doped with about 600 ppm molar $\mathrm{Yb}_{2} \mathrm{O}_{3}$. The fibre \# 2 (codoped with phosphorous) has a core of $3 \mu \mathrm{m}$ diameter and is doped with about $85 \mathrm{ppm}$ molar $\mathrm{Yb}_{2} \mathrm{O}_{3}$. The guided light output emission is focused onto the entrance slit of a double Czerny-turner monochromator equipped with two $1800 \ell / \mathrm{mm}$ gratings. At the exit slit, we used a cooled $6256 \mathrm{~S}$ photomultiplier as a detector.

Optical fibres doped with rare-earth ions have been mainly developped for use as both optical amplifiers and lasers $[1,2]$. These devices are of considerable importance since their operating wavelengths coincide with the third window centered around $1.55 \mu \mathrm{m}$. The Ytterbium ion was also used as an activator ion in the codoped fibres, for example: with $\mathrm{Er}^{3+}$ [3] and $\mathrm{Pr}^{3+}$ [4-6].

Even if it is well known that the $\mathrm{Yb}^{3+}$ ion does not exhibit any transitions in the visible range, we show in this experiment that the fibre emits a blue-green luminescence when excited in the nearinfrared. This is tentatively explained by a cooperative phenomenum. The experimental visible spectrum is in good agreement with a theoretical self-convolution (fig 1) of the single-ion fluorescence spectrum. Figure 2 shows how a resulting visible frequency : $v=v_{\text {donor }}+v_{\text {acceptor }}$ is obtained, the cooperative luminescence transfer rate being a function of the product of the fluorescence cross-section: $\Lambda(v)=\Lambda_{\mathrm{e}}\left(v_{\text {donor }}\right), \Lambda_{\mathrm{e}}\left(v_{\text {acceptor }}\right)$.

These cooperative processes are well known in highly doped materials both in crystals [7], and in glasses [8] as this luminescence effect was first observed by Nakazawa and Shionoya in 1970 [9]. Figure 3 shows that the cooperative luminescence power reaches a maximum when the Amplified Spontaneous Emission (ASE) power begins to grow. For the fibre \# 2, the threshold of the singlepass retrodiffused ASE is around $60 \mathrm{~mW}$ in absorbed pump power at an excitation wavelength of 
$900 \mathrm{~nm}$. While it appears at around $12 \mathrm{~mW}$ for fibre \# $1(875 \mathrm{~nm})$. Beyond this ASE threshold, any additional excitation power is directly converted into ASE power and the cooperative luminescence intensity is clamped.

The ASE threshold depends on the pumping saturation power of the fibre. This saturation power is defined as : $P_{s a t}=\frac{h \cdot v_{p}}{\sigma_{p} \cdot \tau} \cdot \pi \cdot W_{p}^{2}$ where $v_{p}$ is the pumping frequency, $\sigma_{p}$ is the excitation absorption cross-section and $\tau$ is the lifetime of the excited state level ${ }^{2} \mathrm{~F}_{5 / 2} . \mathrm{W}_{\mathrm{p}}$ is the pump waist mode profile very close to the fiber core radius.

At $900 \mathrm{~nm}$, the saturation power of the fibre $\# 2$ is approximately $3 \mathrm{~mW}$ while the saturation power of the fibre \#1 is approximately $1.5 \mathrm{~mW}$.

Finally, figure 4 shows the evolution of the cooperative luminescence intensity as a function of the absorbed pump power for the two fibres. The fiber lengths are $3 \mathrm{~m}$ and $28 \mathrm{~m}$ for fibre \#1 and \#2 respectively. The differences of threshold can be attributed to the difference in the waist of the mode profiles and the different excitation wavelengths ( $900 \mathrm{~nm}$ for fibre \#2 and $875 \mathrm{~nm}$ for fibre \#1).

As a conclusion, a cooperative luminescence phenomena has been observed in low doped ytterbium silica fibres. The spectral distribution is in agreement with a self-convolution of the single ion fluorescence spectrum. However, a question is raised by the power dependence of the cooperative luminescence intensity. The fact such effect is observed at very low concentration compare to other observations may be related to pair formations in the silica glass net. A carefull study of fluorescence dynamics needs to be done to probe the real existence of this cooperative phenomena.

\section{References:}

[1] P. Urquhart

IEE proc. J, vol 135, 385, (1988)

[2] S. Magne

PhD Thesis, Université de Saint-Etienne, France (1993)

[3] W. L. Bames, S. B. Poole, J. E. Townsend, L. Reekie, D. J. Taylor and D. N. Payne

J. of Light. Tech., 7, 10, 1461 (1989)

[4] D. Piehler, D. Craven, N. Kwong and H. Zarem

Electron. Lett., 29, 1857 (1993)

[5] Y. Oshisi, T. Kanamoni, T. Nishi,S. Takahashi and E. Snitzer

IEEE Phot. Tech. Lett., 3, 990 (1991)

[6] J. Y. Allain, M. Monerie and H. Poignant

Electron. Lett., 27, 1156 (1991)

[7] V. V. Ovsyankin, in "Spectroscopy of solids containing rare-earth ions"

Eds. A. A. Kaplyanskii and R. M. Macfarlane, (North Holland, Amsterdam) (1987)

[8] A. V. Dmitryuk, G. O. Karapetyan, V. I. Kosyakov, B.M. Makushkin and V.A.

Shirokshin, Opt. Spectrosc., 37, 335, (1974)

[9] E. Nakazawa and S. Shionoya, Phys. Rev. Lett., 25, 1710, (1970) 


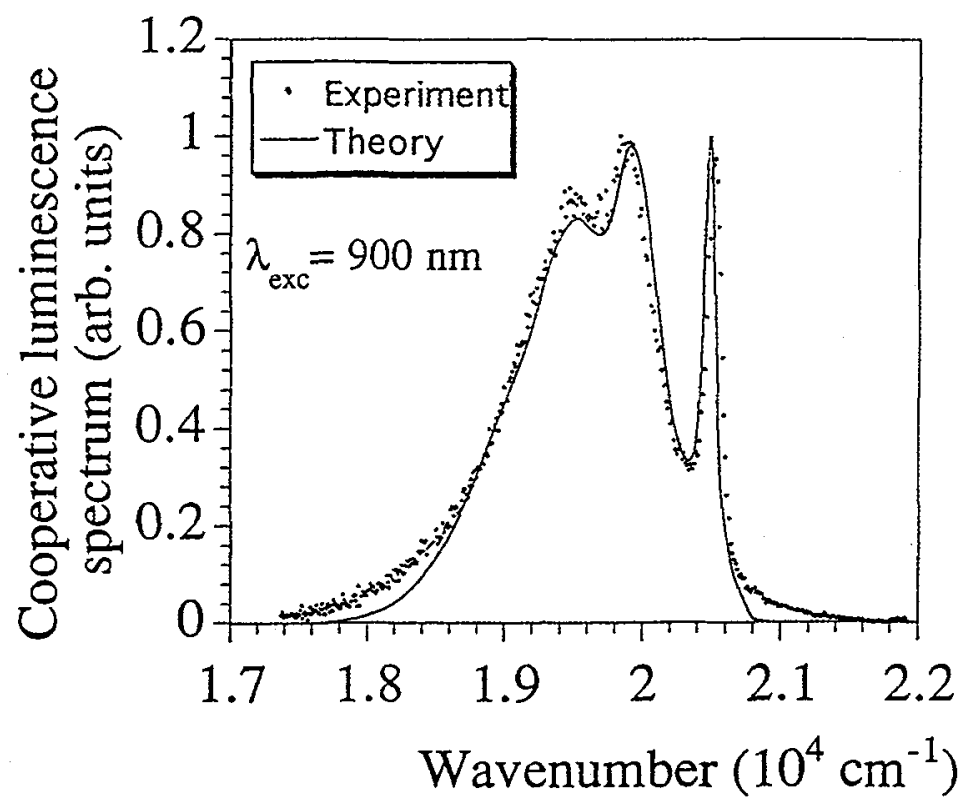

Fig 1 : Comparison between experimental and calculated site-selective cooperative luminescence spectra (excitation wavelength : $900 \mathrm{~nm}$ ).

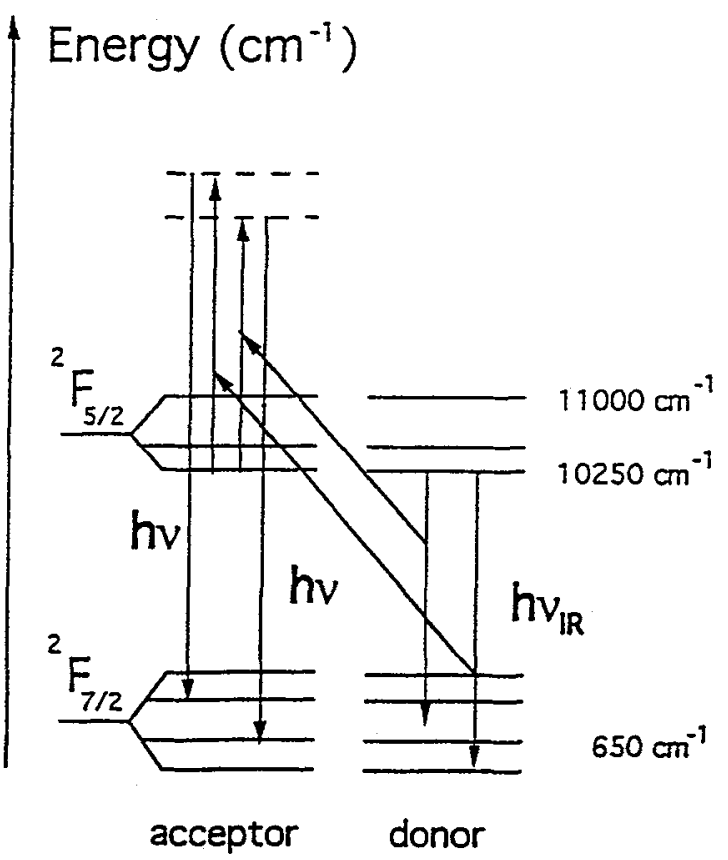

Fig. 2 :Cooperative luminescence process schematic diagram. 


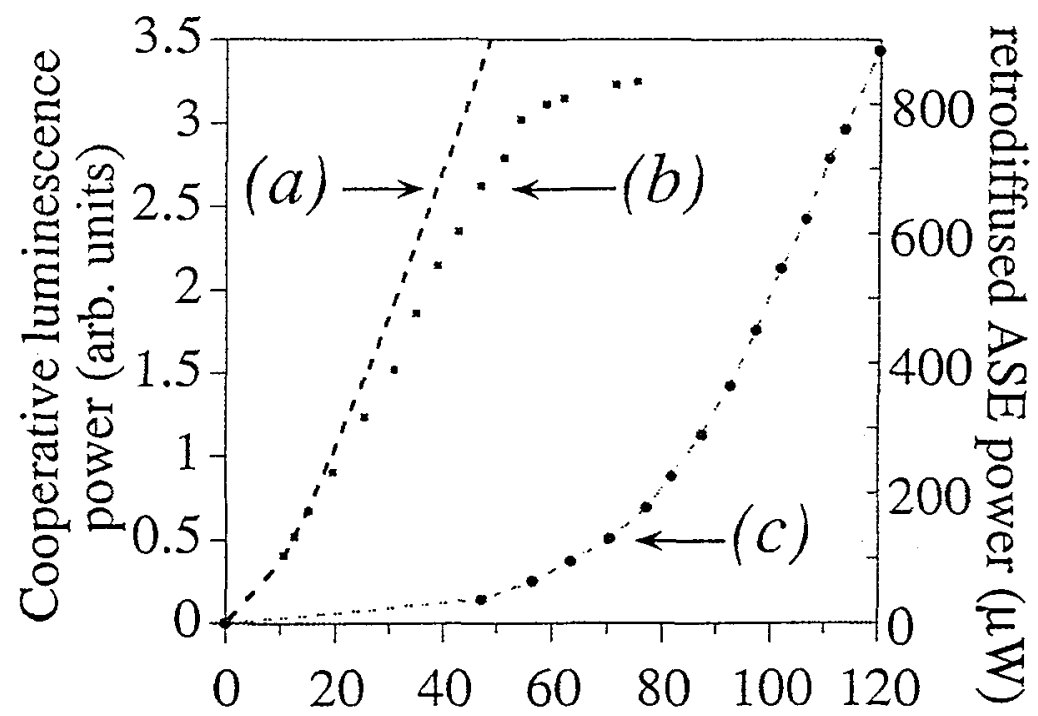

\section{Absorbed excitation power (mW)}

Fig . 3 : Evolution of the cooperative luminescence power ( (a) theory neglecting the ASE saturation - (b) experiment \} and the retrodiffused ASE power (c) with respect to absorbed excitation power (excitation wavelength : $900 \mathrm{~nm}$, the fibre\#2 is $28 \mathrm{~m}$ long).

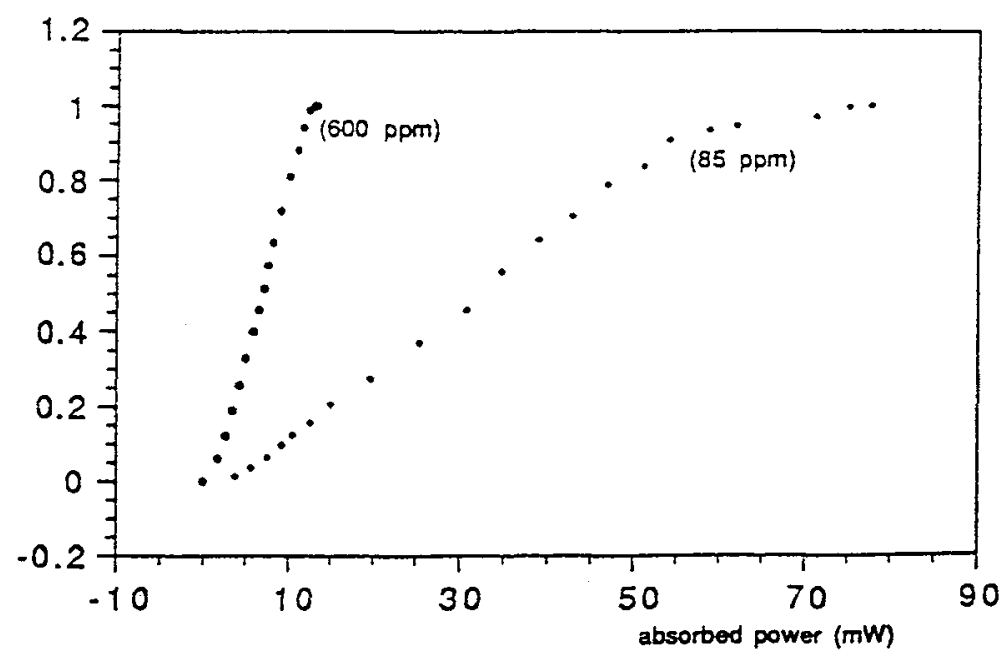

Fig. 4 : Evolution of the cooperative luminescence power with respect to absorbed excitation power for fiber \#1 and \#2. 